Evaluation et Gestion de la carriere de la femme - Henriette, M. Evaluation et Gestion de la cantere
de la femme. La femme, africaine spécifiquement, subit sa carrière. Elle devrait pourtant la géré
son épanouissement, et pour un meilleur apport dans sa famille et la société.

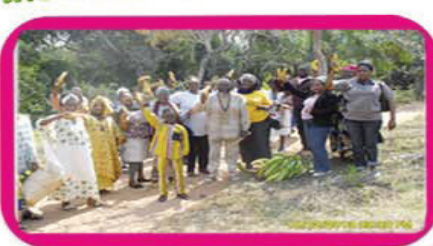

Pour gérer sa carrière à satisfaction, il est impératif de sortir des situations d'inconfort, si l'on ne se sent pas bien dans une boîte, l'on commence à scruter dans son environnement. Les mouvements peuvent être verticaux ou domaine carrément. La femme saura ainsi donner à sa carrière le sens qui lui plait si elle la gère au lieu de la subir. Débats, Commerce, arts, Agriculture, Elevage.... qu'il conviendrait de valoriser.

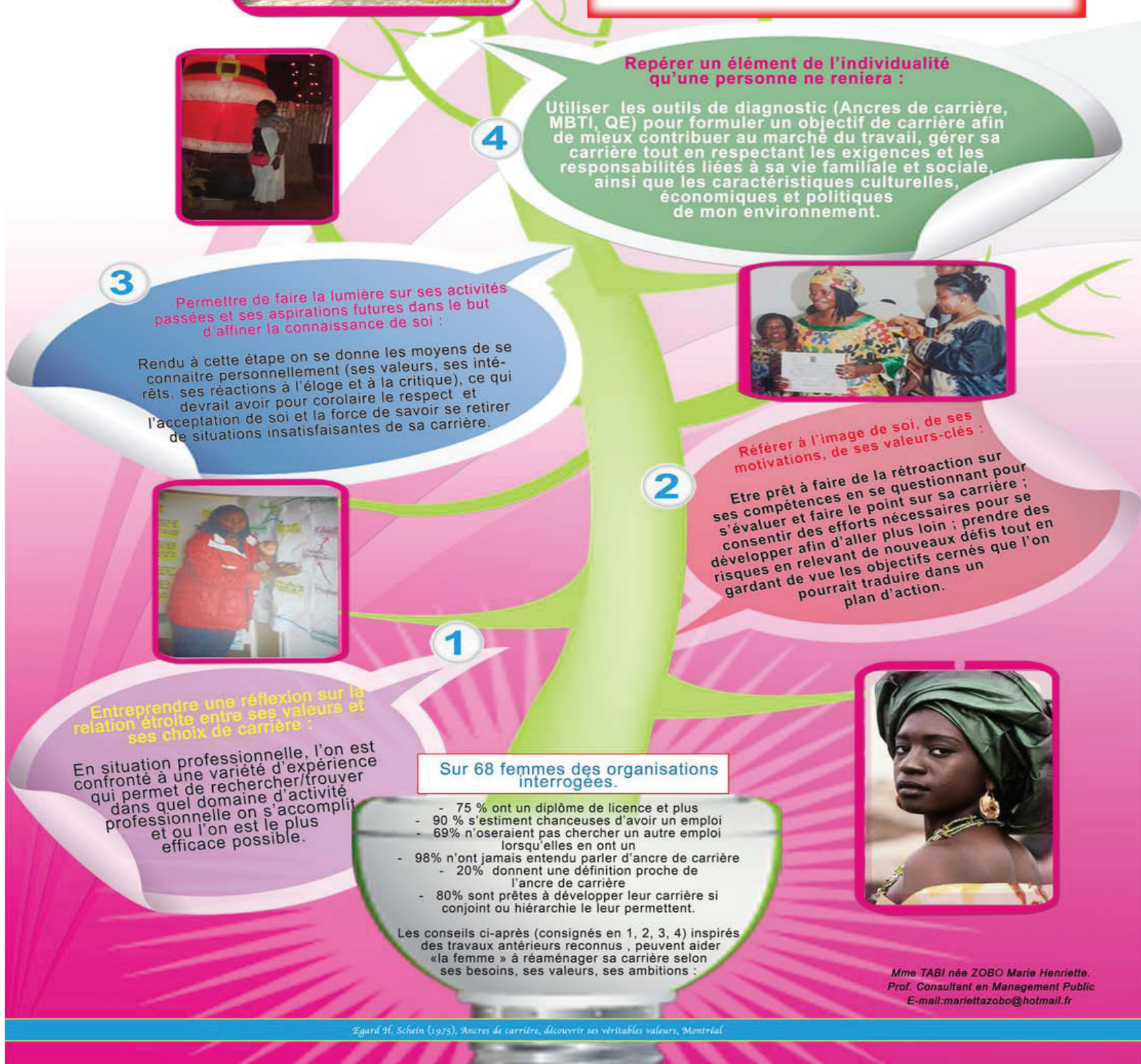

Source: Author's original material as presented at the conference

\section{Read online:}

回㨁回 Scan this QR

code with your

smart phone or

15. mobile device

G 7 to read online.
How to cite this poster: Henriette, M., 2014, 'Evaluation et gestion de la carriere de la femme', African Evaluation Journal 2(1), Art. \#104, 2 pages. $h$ ttp://dx.doi.org/10.4102/aej.v2i1.104

Note: The poster was presented at the 7th African Evaluation Association (AfrEA) conference held in Yaounde, Cameroon, 1-5 March 2014 Copyright: (c) 2014. The Authors. Licensee: AOSIS OpenJournals. This work is licensed under the Creative Commons Attribution License. 
Evaluation et Gestion de la carriere de la femme - Henriette, M. (Continues...)

\section{Evaluation et Gestion de la carriere de la femme}

La femme, africaine spécifiquement, subit sa carrière. Elle devrait pourtant la gérer pour son épanouissement, et pour un meilleur apport dans sa famille et la société.

Une enquête sur la carrière de la femme, que j'ai réalisé auprès de 68 femmes des organisations ayant au moins un diplôme de licence, a montré que $80 \%$ d'entre elles au moins, reconnaissent qu'avoir un emploi est une chance et que se mettre encore à réinterroger sa carrière aux fins d'en arriver à une évaluation et pouvoir la gérer au mieux n'est pas opportun.

Les conclusions de notre étude consignées dans ce Poster, leurs proposent sur la base des travaux d'un auteur reconnu ${ }^{1}$, des orientations qui peuvent l'aider « la femme» à réaménager sa carrière selon ses besoins, ses valeurs, ses ambitions, ainsi elle devrait:

- Entreprendre une réflexion sur la relation étroite entre ses valeurs et ses choix de carrière,

- Référer à l'image de soi, de ses motivations, de ses valeurs-clés,

- Permettre de faire la lumière sur ses activités passées et ses aspirations futures dans le but d'affiner la connaissance de soi,

- Repérer un élément de l'individualité qu'une personne ne reniera.

Aux fins de gérer sa carrière à satisfaction, il est impératif que la femme évalue sa carrière dans le but de sortir des situations d'inconfort, elle saura ainsi donner à sa carrière le sens qui lui plaitsi elle la gère au lieu de la subir. C'est reconnu, elle a des aptitudes dans divers domaines: Formations, Conférence, Débats, Commerce, arts, Agriculture, Elevage... qu'il conviendrait de valoriser.

Madame TABI née ZOBO Marie Henriette 